\title{
RESÍDUO TÊXTIL: MATÉRIA-PRIMA PARA PRODUTOS DE ECONOMIA SOLIDÁRIA
}

\section{RAW MATERIAL FOR SOLID ECONOMY PRODUCTS}

\author{
Neide Schulte, Dra . (UDESC); \\ Vitória Voltolini de Almeida (UDESC); \\ Beatriz Liston Salinas (UDESC).
}

\section{Palavras Chave}

Resíduos têxteis, economia solidária, ecomoda.

\section{Key Words}

Textile waste, solidarity economy, ecological fashion

\section{RESUMO}

Esse trabalho apresenta alguns impactos da indústria da moda, mais especificamente o problema do volume de resíduos têxteis gerado na confecção de roupas. Esses resíduos, se coletados adequadamente, podem ser utilizados como matéria-prima em empreendimentos de Economia Solidária. Além de contribuir na redução dos impactos da indústria da moda, o reuso desses resíduos também é uma solução para a minimização do desemprego e a reinserção social de reeducandas de presídios.

\section{ABSTRACT}

This paper presents some of the impacts of the industry fashion. Specifically the problem of the volume of textile waste generated in the manufacture of clothes. These residues, if properly collected, can be used as raw material in Solidarity Economy projects. In addition to contributing to reduction the fashion industry impacts, the reuse of these wastes is also a solution for vthe minimization of unemployment and the social reintegration of prisons. 


\section{INTRODUÇÃO}

O equilíbrio entre as necessidades humanas e a preservação do meio em ambiente natural é um debate antigo, que tem tomado força no mundo contemporâneo com o avanço tecnológico, as mudanças globais na economia, na sociedade e, principalmente, no clima do planeta Terra. A concepção de modelos de desenvolvimento harmônico tem sido uma busca da sociedade, do mercado, de governos e da própria ciência.

O debate na sociedade sobre sustentabilidade deixou de ser uma novidade. Tornou-se um assunto do cotidiano, cada vez mais comum, na tentativa de sensibilizar as pessoas sobre o impacto da produção e do consumo humano, bem como sobre a importância da preservação do meio ambiente natural. Atualmente, diversas organizações, empresas e pessoas estão desenvolvendo ações para reparar e minimizar os impactos desse cenário de destruição acelerada da natureza. Gradativamente vem sendo incorporada a preocupação com a responsabilidade socioambiental na tentativa de minimizar os efeitos causados pelo modo de vida dos humanos.

A indústria da moda, mais especificamente ligada ao vestuário, gera impactos socioambientais graves nos diversos setores da sua cadeia produtiva, da produção da matéria-prima até o varejo e descarte das roupas. Diante desses impactos, vem sendo pesquisadas alternativas para melhorar esse cenário. O aproveitamento dos resíduos como matéria-prima para outros produtos, por exemplo, contribui na redução de lixo e na geração de renda.

Esse trabalho apresenta alguns impactos da indústria da moda, mais especificamente o problema do volume de resíduos têxteis gerado na confecção de roupas. Esses resíduos, se coletados adequadamente, podem ser utilizados como matéria-prima em empreendimentos de Economia Solidária. Além de contribuir na redução dos impactos da indústria da moda, o reuso desses resíduos também é uma solução para a minimização do desemprego, por caminhos não necessariamente vinculados ao trabalho assalariado.

Para evidenciar a importância de capacitações para reuso de materiais têxteis, é apresentado o projeto Capacitação em Ecomoda, que foi executado numa parceria entre o Programa de Extensão Ecomoda Udesc, o Instituto Trama Ética, o GIOS - Grupo Integrado Obras Sociais e o PRT - Presídio Regional de Tijucas, com apoio financeiro do PAP Acif de Florianópolis. O projeto foi realizado no GIOS, situado no Centro de Florianópolis, no Ceart/Udesc e no Presídio Regional de Tijucas.

\section{IMPACTOS DA INDÚSTRIA DA MODA}

A cadeia da indústria da moda abrange uma extensa lista de setores, da produção da matéria-prima até o varejo, com uma produção têxtil que, por um lado gera índices positivos na economia, e por outro lado gera impactos socioambientais negativos.

São muitos os impactos negativos do atual sistema de moda. Entre os principais danos causados à natureza e ao ser humano está o uso de agrotóxicos nos cultivos de algodão e a utilização de produtos químicos durante todo o processo de fabricação de uma roupa, além de outros problemas como o uso de mão-de-obra infantil, escrava e semi-escrava (SCHULTE, p 52, 2015).

De acordo com os dados da Associação Brasileira da Indústria Têxtil e de Confecção (ABIT, 2016), as confecções brasileiras produziram em 2015 uma média de 5,5 bilhões de peças (incluindo cama, mesa e banho), enquanto que as indústrias têxteis tiveram uma produção média de 1,9 milhão de toneladas. Tais setores foram responsáveis por 9,5 miIhões de trabalhadores diretos e indiretos, dos quais $75 \%$ são mulheres. Isto eleva a cadeia têxtil como segunda maior empregadora da indústria de transformação. O Brasil se destaca como quinto maior produtor têxtil do mundo, emergindo como um dos principais responsáveis pela geração de resíduos nocivos ao meio ambiente (MENEGUCCl, et al., 2015).

No processo para o desenvolvimento de produtos do vestuário, é produzida grande quantidade de resíduos. São toneladas de retalhos muitas vezes descartadas de modo irregular em aterros sanitários e isso representa um grande problema para as empresas e contribui para o acúmulo de resíduos no Brasil (MENEGUCCl, et al., 2015).

O setor de corte das peças de roupa é o maior gerador de resíduos têxteis em relação a outros setores, pois a modelagem das peças não se encaixa perfeitamente, por respeitar o formato anatômico e curvo do corpo humano. Desses retalhos de tecido gerados a partir das peças cortadas, cerca de 12\% (AMARAL; BARUQUE; FERREIRA, 2014), no Brasil, somam em um ano cerca de 175 mil toneladas. Dessa quantidade, apenas $20 \%$ são reaproveitados para a fabricação de novos produtos, como barbantes, mantas, novas peças de roupa e fios (TURCl, 2012 apud FREIRE e LOPES, 2013). São descartadas pelas empresas 139 mil toneladas, na maioria das vezes de forma inadequada, ao misturá-las com o lixo comum, inviabilizando o reaproveitamento e ainda transformando-as em agentes de contaminação de recursos naturais.

É importante destacar que tais problemas se traduzem não apenas como fatores de poluição, mas também como prejuízo econômico para o país. Segundo pesquisa de 
Martins (2015), foram contabilizados os gastos aproximados que a indústria brasileira teve em 2011 com resíduos têxteis, aproximadamente $\mathrm{R} \$ 5$ bilhões. Dentro dessa quantia estão os custos da matéria-prima desperdiçada. Além disso, no mesmo ano, o Brasil importou 13 mil toneladas de resíduos, por um preço de US\$ 13 milhões, mesmo tendo capacidade para suprir sua própria demanda por este tipo de material.

Para a fabricação de fios, barbantes e tecidos reciclados é necessário que o resíduo esteja limpo, separado por cor e por composição. A desorganização da coleta de resíduos têxteis no Brasil é tão grave que as indústrias recicladoras, que precisam abastecer diariamente suas unidades produtivas, preferem importar resíduos têxteis de outros países, pois os fardos importados já chegam separados (AMARAL; BARUQUE; FERREIRA, 2014).

A má gestão dos resíduos tem resultado num elevado custo para as empresas do setor, uma média de R\$ 254 mil por ano, conforme a figura 1, acarretando também no aumento do valor do produto final.

Figura 1: Esquema dos gastos com resíduos têxteis.

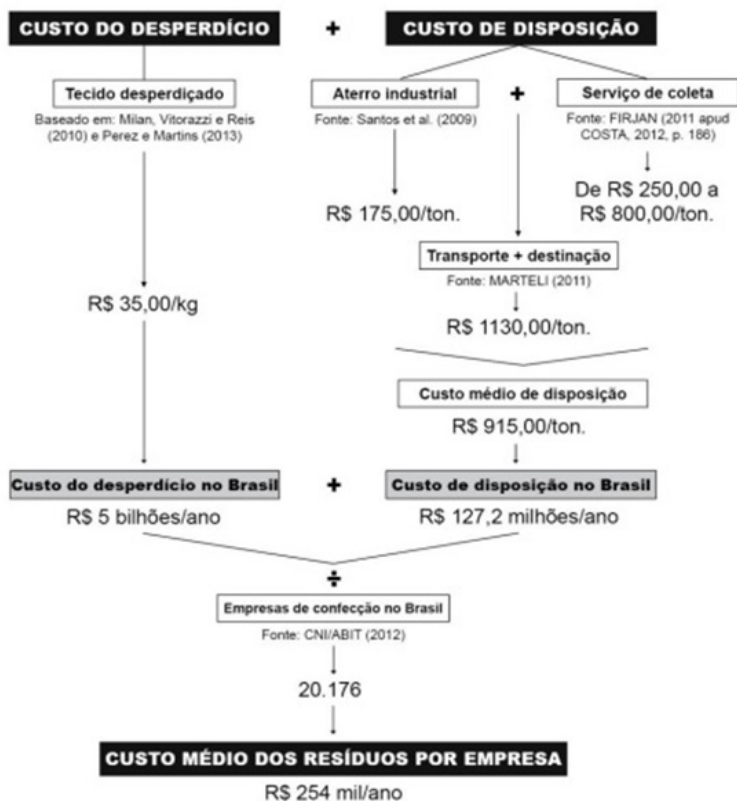

Fonte: Martins, 2015, p. 3.

Se houvesse mais cuidado na coleta e na separação dos resíduos têxteis no Brasil, esse material poderia ser reutilizado como matéria-prima para diversos produtos, através da logística reversa, exemplificada na Figura 2.
Figura 2: Possibilidade de destinação do resíduo têxtil

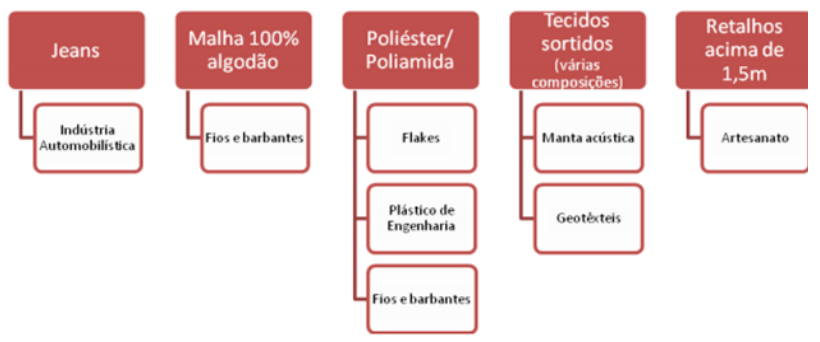

Fonte: Amaral; Baruque; Ferreira, 2014.

Na busca por soluções para a indústria têxtil e do vestuário, é necessário compreender que existem muitas possibilidades, e é preciso repensar todos os processos do ciclo de vida dos produtos. Entre as possibilidades está o aproveitamento de resíduos têxteis como matéria-prima em empreendimentos de economia solidária.

\section{A ECONOMIA SOLIDÁRIA (ES) NO CON- TEXTO BRASILEIRO}

A prática econômica fundamentada no solidarismo nasceu de uma crítica ao cooperativismo agroindustrial, que predominou no Brasil até meados do século $X X$. Seus ideais se alicerçavam nos princípios da autonomia e nos embates em prol da redemocratização do país. Os principais sujeitos fomentadores destas práticas atuavam, de modo geral, na reestruturação dos processos democráticos do país, representados coletivamente por instituições ou organizações como sindicatos, igrejas, universidades, organizações não governamentais e partidos de esquerda (BARBOSA, 2007).

A constituição do campo da Economia Solidária no Brasil ocorreu simultaneamente à articulação das práticas nas esferas políticas, econômicas e sociais. No Brasil, especialmente a partir da década de 1980, ocorreram profundas transformações nas estruturas socioeconômicas que provocaram efeitos contundentes no âmbito do trabalho e a consequente busca dos trabalhadores por sua própria subsistência, o que possibilitou a sublevação de iniciativas solidárias como categorias de reivindicação de demandas sociais, políticas e econômicas (SILVA; SCHULTE, 2014).

Neste período, iniciativas associativistas e ações políticas orientadas às melhorias sociais, sustentaram a estruturação da Economia Solidária no âmbito do Estado, como parte de uma resignificação semântica, política, econômica e social do trabalho (BARBOSA, 2007), que visava estabelecer seu reconhecimento principalmente 
pelas contingências da cultura do autoemprego, desvinculando-a da crise do trabalho e da queda qualitativa das vantagens empregatícias.

Neste panorama de precarização e desigualdade, emerge a Economia Solidária, pautada ora como uma categoria econômica diferenciada e autônoma, ora como um conceito ou movimento social. Embora não exista um consenso sobre seu enquadramento prático e teórico, as experiências que deram origem à Economia Solidária foram determinadas por variados modos de associação e organização de trabalhadores na iminência do desemprego ou no limiar da informalidade e da precarização, em uma tentativa de resgate dos princípios de solidariedade e de autogestão, tendo em vista uma redemocratização social e econômica.

A crise contemporânea do trabalho e do emprego que tem marcado o sistema socioeconômico ocidental durante o século XX até o início do século XXI, se encontra diretamente atrelada à ampliação máxima das forças produtivas inerentes aos modelos fundamentados no fordismo e no keynesianismo, na fragilidade das forças reguladoras do Estado e na expansão em níveis mundiais das forças produtivas, distributivas e de acumulação (BARBOSA, 2007). A soma destes fatores ultrapassou os mecanismos de controle exercidos pelo sistema e, em favor de novos modelos produtivos e de valorização do capital, os índices de desemprego se ampliaram sobremaneira, provocando mudanças nas relações de trabalho e nos sistemas de produção, resultando na flexibilização do trabalho e do trabaIhador, na precarização das condições de trabalho e nos índices crescentes de desemprego em escala mundial.

Deste modo, as estruturas que fundamentam o mundo do trabalho passaram a ser ordenadas globalmente pelas oscilações do capital no último quartel do século $X X$, sofrendo rearranjos em suas bases para dar lugar a novos modos de produção e controle (FARIA, 2011). A reestruturação dos arranjos produtivos alterou as condições organizacionais e a gestão do trabalho e fragilizou a condição do trabalhador, mas convém ressaltar que também se mostrou com uma vantajosa alternativa, uma vez que atuou no fortalecimento do modo de acumulação e de concentração de capital.

Com as mudanças que ocorreram no mundo do trabaIho e com o consequente aumento da massa de desempregados no Brasil no final do século XX, o sindicalismo transfere suas ações mais reivindicatórias de oposição ao poder público e ao empresariado, para atuar em favor de soluções mais tangíveis. Assim, passa a colaborar com ações no âmbito da Economia Solidária, que ampliam as possibilidades de trabalho e emprego, pois a identifica como um meio de resgate dos indivíduos das margens do sistema.

O desenvolvimento da Cooperativa Central e Economia Solidária (ECOSOL), a partir de sua constituição em 2002, apresenta como meta integrar regionalmente as instituições financeiras de base solidária a fim de promover o desenvolvimento local. Devido à grande quantidade de cooperativas de crédito com enfoque solidário, em 2004 foi criada a Associação Nacional do Cooperativismo de Crédito de Economia Familiar e Solidária (ANCOSOL), tendo em vista congregar o segmento cooperativo brasileiro atuante no âmbito das finanças solidárias (ANCOSOL, 2012). A Central de Cooperativas e Empreendimentos Solidários (UNISOL Brasil), criada no ano 2000, também se originou a partir das proposições da ADS/CUT e se estabeleceu como uma instituição representante das cooperativas brasileiras fundamentadas na autogestão e na Economia Solidária (UNISOL Brasil, 2012).

Estas iniciativas constituídas por sujeitos coletivos juntamente com as políticas públicas iniciadas pelo governo no final do século XX marcam pela primeira vez a busca de soluções para a minimização do desemprego, por caminhos não necessariamente vinculados ao trabaIho assalariado (BARBOSA, 2007).

O campo da Economia Solidária no Brasil passou a ser reconhecido como um fenômeno socioeconômico, que parte dos preceitos da solidariedade para fundamentar as ações econômicas desenvolvidas sob suas linhas diretivas. As teorias e as práticas que arregimentam o campo avançam sob um amplo universo de fundamentações que se baseiam em características comuns, como a autogestão, a cooperação e o associativismo (SILVA; SCHULTE, 2014).

Segundo o MTE/SENAES (2013) este conjunto de atividades econômicas se caracteriza por seu modo organizacional diferenciado, fundamentado em modelos de cooperação e associativismo, clubes de troca, autogestão, redes, entre outros modos mais horizontalizados de desenvolvimento. Este delineamento se materializa nos modelos econômicos de produção, distribuição, consumo, poupança e crédito desenvolvidos sob princípios solidários como um modo de combate ao desemprego e a exclusão social.

Estes princípios solidários se caracterizariam principalmente em ações de amparo ao setor, a partir de preceitos que garantam a compra e venda dos produtos e serviços entre os empreendedores; propiciem uma produção diversificada de produtos e serviços; a livre concorrência entre empresas solidárias tendo em vista a redução dos custos e a ampliação da qualidade; o desenvolvimento de uma moeda própria e apoio do Estado no fornecimento de crédito, treinamento, assistência tecnológica e políticas de fomento (CASTRO, 2009). 


\section{EMPÓRIO DE ECONOMIA SOLIDÁRIA EM FLORIANÓPOLIS -SC}

O Fórum Regional de Economia Solidária de Florianópolis é uma organização informal que surgiu em 2005 a partir da necessidade de criar e fortalecer uma rede local de apoio aos empreendimentos que já existiam e auxiliar na criação de novos empreendimentos, com base nos princípios da Economia Solidária. É formado por representantes de entidades de apoio e fomento, gestores públicos das esferas municipal, estadual e federal e empreendimentos de Economia Solidária da área urbana e rural e, com outros nove fóruns regionais, compõem o Fórum Catarinense de Economia Solidária.

Entre os empreendimentos participantes do Fórum, surgiu a demanda por um espaço fixo para comercialização de produtos da Economia Solidária. A partir de tratativas com a Prefeitura Municipal de Florianópolis, - IGEOF disponibilizou o box 46 no Mercado Público de Florianópolis e, em 15 de dezembro de 2015 foi inaugurado o Empório da Economia Solidária.

Desde a abertura, o Empório da Economia Solidária tem sido administrado por um grupo de pessoas ligado a empreendimentos de Economia Solidária participantes do Fórum Catarinense de Economia Solidária. A gestão do box 46 tem sido um desafio para todos os participantes, que estão passando por um processo de aprendizado, vivenciando e praticando a Economia Solidária. O grupo está buscando capacitações para aprimorar conhecimentos e abrindo espaço para novos empreendimentos participarem.

O Empório de Economia Solidária estabeleceu em seu Regimento Interno os seguintes objetivos:

a) Promoção dos direitos humanos respaldados na solidariedade, na ética e na democracia.

b) Desenvolvimento sustentável, com foco nas relações sociais e produtivas, fundamentado nos preceitos de comércio justo e solidário, e com participação dos produtores em todas as fases do processo da cadeia produtiva.

c) Controle de ações que estimulem e garantam a prática efetiva da autogestão e da cooperação numa proposta social, econômica e solidária.

d) Valorização e estimulação de cultura popular.

e) O auxílio mútuo e o desenvolvimento de projetos sociais e culturais, observando os princípios da legalidade, transparência, impessoalidade, moralidade, economicidade e da eficiência, sem discriminação de raça, cor, gênero, religião ou classe social.

Um dos propósitos do Empório da Economia Solidária é o incentivo à utilização de materiais da região, materiais recicláveis, biodegradáveis e não poluentes, tendo sempre em mente a preservação ecológica.

Os empreendimentos que participam do Empório da Economia Solidária desenvolvem produtos tendo como prioridade o uso de materiais descartados por empresas têxteis e outros resíduos, bem como o uso de materiais de baixo impacto ambiental.

O Empório da Economia Solidária tem sido uma oportunidade para os empreendimentos que encontram dificuldades na comercialização de seus produtos, além disso, tem sido um espaço para aprendizagem, compartiIhamento de dificuldades, saberes e conhecimentos.

Com a instabilidade econômica mundial, a crise nos empregos formais e um cenário futuro onde a economia criativa tem sido o caminho para geração de renda e sobrevivência para muitas pessoas, o Empório da Economia Solidária é uma conquista muito importante para a região da Grande Florianópolis. O que significa para os empreendimentos participantes um compromisso e uma grande responsabilidade perante a sociedade, organizar, manter e aperfeiçoar o Empório da Economia Solidária.

O grupo tem se empenhado para superar as dificuldades. Seus participantes têm buscado superar questões de ego, entendendo que na Economia Solidária é preciso pensar de forma coletiva, agindo de modo que o crescimento pessoal e do grupo sejam paralelos. Ou seja, ninguém cresce sozinho se o grupo não crescer. Essa visão de mundo é fundamental para superação dos problemas gerados pelo capitalismo.

Uma formação continuada para gestão do Empório e o aperfeiçoamento dos produtos em qualidade e responsabilidade socioambiental é a meta do grupo. Com o empenho de todos os participantes, e de novos que poderão agregar com novos produtos, o Empório da Economia Solidária de Florianópolis pode se tornar uma referência para que outras prefeituras proporcionem espaços para comercialização.

\section{CAPACITAÇÃO EM ECOMODA: ÊNFASE EM REUSO DE RESÍDUOS TÊXTEIS}

Com o apoio do PAP - Programa de apoio a projetos da ACIF - desenvolveu-se o projeto Capacitação em Ecomoda. O projeto foi executado numa parceria entre o Programa de Extensão Ecomoda Udesc, o Instituto Trama Ética, o GIOS - Grupo Integrado Obras Sociais e o Presídio Regional de Tijucas. O projeto foi realizado no GIOS, situado no Centro de Florianópolis, no Ceart/Udesc e no Presídio Regional de Tijucas.

O projeto foi uma ação para ampliar a atuação do GIOS e do Instituto Trama Ética, oferecendo capacitação em ecomoda visando geração de trabalho e renda para 
mulheres e jovens de comunidades de baixa renda, e reeducandas de presídios da Grande Florianópolis.

Durante o projeto, realizado de março a outubro de 2016, foram ministrados cursos, oficinas e palestras sobre o tema ecomoda e economia solidária, dando ênfase no reuso de resíduos têxteis (figura 3), na reutilização de roupas, no uso de materiais reciclados e nas técnicas manuais do saber da cultura local (renda de bilro, crochê e bordado).

Figura 3: Uso de resíduo têxtil em colcha infantil com técnica de bordado selvagem

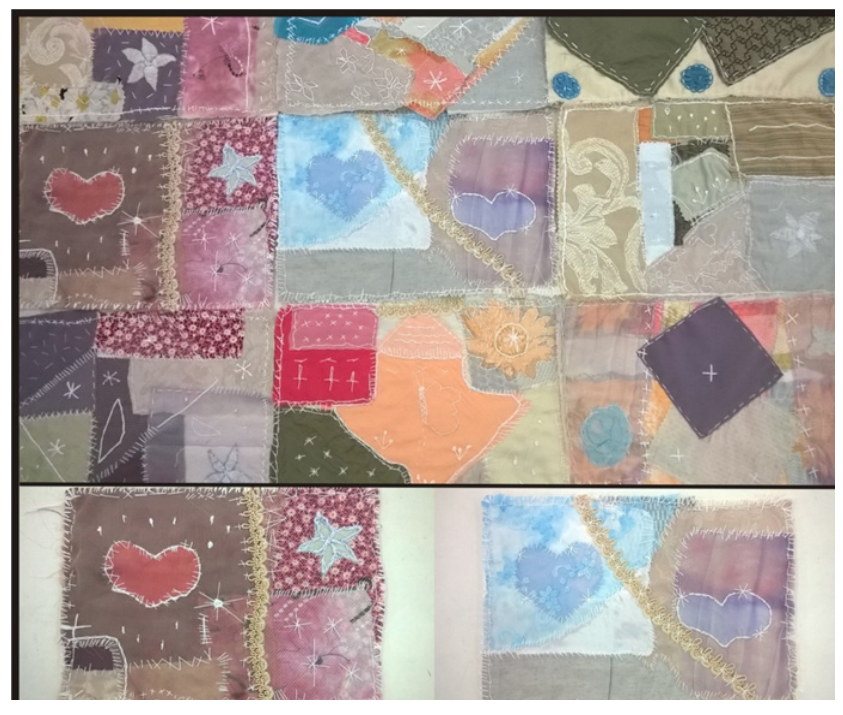

Fonte: Acervo pessoal, 2016.

A colcha infantil foi feita pelas reeducandas do Presídio Regional de Tijucas, utilizando pequenos retalhos descartados por confecções da Grande Florianópolis. Cada participante recebeu um tecido, para usar como superfície, e retalhos para fazer uma composição que foi aplicada com pontos à mão e bordados, técnica denominada bordado selvagem, ou livre.

O bordado selvagem pode ser aplicado em peças de vestuário (customização), em almofadas, cúpulas e em outras peças de decoração. Oficinas de bordado selvagem foram realizadas no Gios, na Udesc e no Presídio Regional de Tijucas.

As peças desenvolvidas têm função educativa para uso em desfiles, exposições, palestras e em outros eventos. São usadas como exemplos em capacitações para pessoas que buscam por oportunidades para geração de trabalho e renda, utilizando materiais que, para as empresas são resíduos, mas nas mãos de artesãos são matérias-primas.

A tecelagem é uma das técnicas artesanais onde podem ser aproveitados os resíduos têxteis. As amostras de tecelagem, com reutilização de retalhos da empresa têxtil Hoepcke e fios reciclados da Eurofios, na figura 4, foram desenvolvidas junto às reeducandas do Presídio Regional de Tijucas e em curso aberto para comunidade na UDESC.

Figura 4: Uso de resíduo têxtil da empresa têxtil Hoepcke em tecelagem

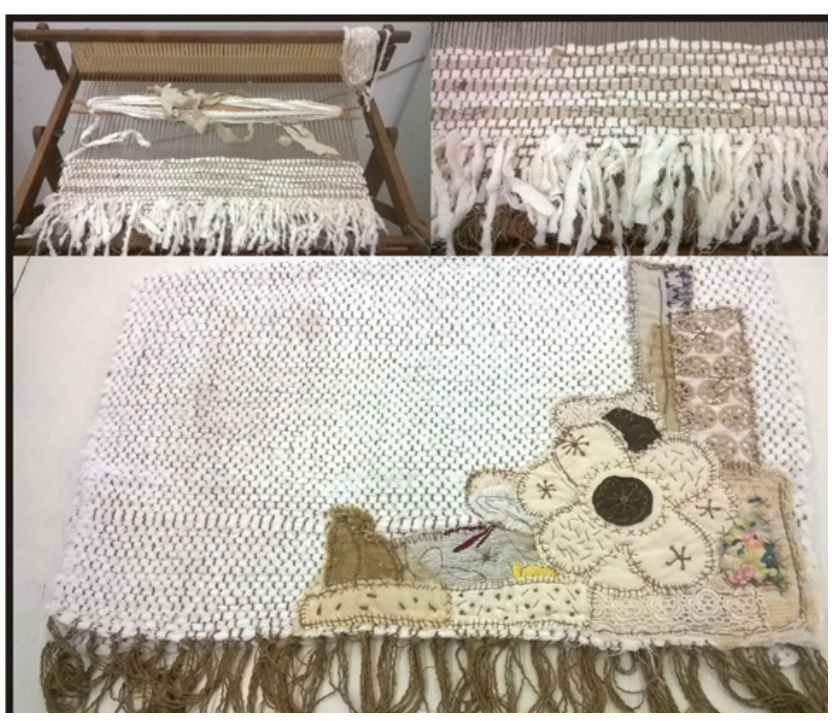

Fonte: Acervo pessoal, 2016.

Além dos resíduos gerados nas empresas de confecção e têxteis em geral, as roupas descartadas pelos usuários também geram problemas ambientais quando descartadas incorretamente.

O tecido utilizado no jeans, por exemplo, é uma matéria prima muito resistente. Após o descarte de roupas de jeans, o tecido pode ser utilizado em diversas aplicações, conforme figura 5.

Figura 5 : Curso de upcycle com jeans

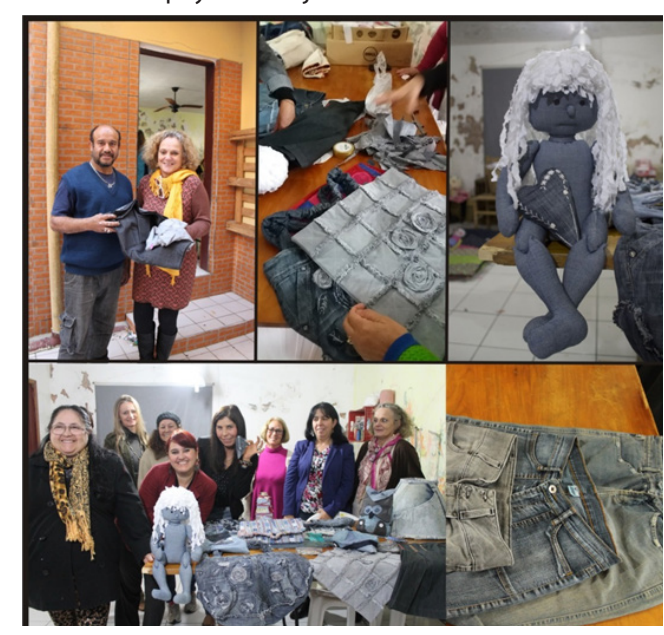

Fonte: Acervo pessoal, 2016.

No curso cada equipe recebeu 3 peças de jeans que foram reutilizadas $100 \%$ para confecção de diversos produtos, ou seja, "lixo zero". O trabalho foi um grande desafio para cada equipe que buscou com muita criatividade aproveitar totalmente as peças de jeans que receberam. 
Como resultados do curso foram apresentados diversos produtos: bonecas, bichinhos, jogos, bolsas, carteiras, almofadas, cúpulas, brincos e muitas outras peças que podem ser desenvolvidas por empreendimentos de Economia Solidária e comercializadas em feiras e em outros locais, como no Empório de Economia Solidária, por exemplo.

As roupas que são descartadas pelos usuários são destinadas geralmente para instituições de caridade que têm brechós beneficentes. O brechó do GIOS recebe roupas que são triadas. As peças que estão em melhores condições são vendidas para arrecadas recursos para manutenção da instituição que produz pijamas para asilos e orfanatos da Grande Florianópolis. As demais peças são doadas para comunidades carentes.

Durante o projeto foram selecionadas peças do brechó do GIOS que foram customizadas a partir de briefing dado pela professora (figura 6). As roupas foram personalizadas, além disso, para cada peça desenvolvida foi feita uma ficha técnica especificando todas as técnicas utilizadas e informações sobre as pessoas que trabalharam na execução.

Figura 6 : Curso de customização de roupas com técnicas artesanais

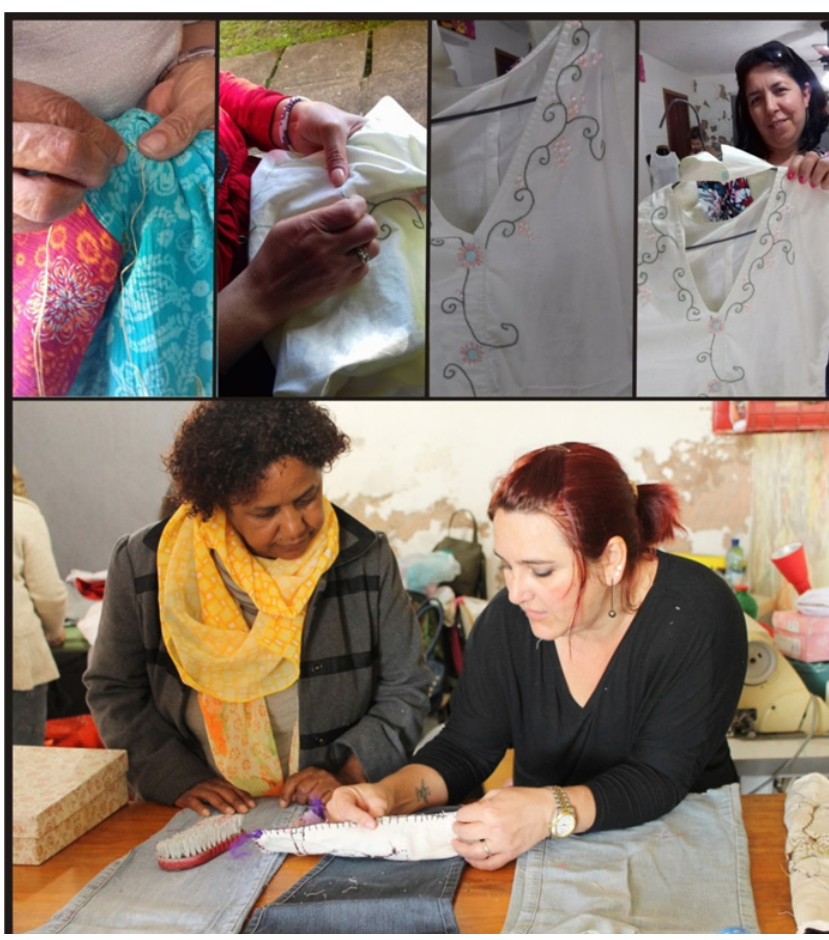

Fonte: Acervo pessoal, 2016

O objetivo foi mostrar para a comunidade todo processo de execução das roupas e as pessoas que participaram do processo. Esse procedimento pretende contribuir para que o consumidor valorize mais as roupas que tem, usando-as por mais tempo e, ao mesmo tempo, ao comprar uma peça, pague um valor justo para quem as produziu. $\mathrm{O}$ trabalho artesanal leva mais tempo para ser realizado e carrega um valor cultural, além de contribuir para a geração de trabalho e renda para as mulheres reeducandas e de comunidades de baixa renda da grande Florianópolis.

As roupas costumam ser descartadas pelos usuários ainda em boas condições, com possibilidades de uso por muito tempo. Roupas de segunda mão, como são chamadas, têm sido uma opção para muitas pessoas que não têm condições de comprar roupas novas, mas também têm sido uma opção para pessoas que querem se vestir com menos o impacto socioambiental.

Além das roupas, peças de mobiliário e decoração também podem ser recuperadas e usadas por mais tempo. O cenário Eco (figura 7) foi construído com peças de mobiliário descartadas, encontradas nas ruas, que foram restauradas com uso de resíduos têxteis nos acabamentos, como no biombo, por exemplo, que tem estrutura de madeira e acabamentos com retalhos de cambraia da empresa Hoepcke.

Figura 7 - Cenário Eco: móveis descartados recuperados e peças feitas com resíduos têxteis

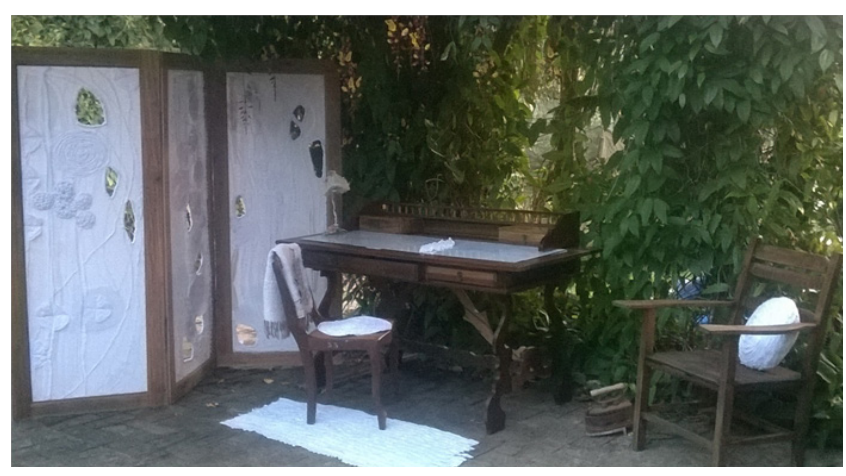

Fonte: Acervo pessoal, 2016

O objetivo principal do projeto Capacitação em Ecomoda foi trabalhar com os alunos questões práticas sobre responsabilidade socioambiental e economia solidária, através da reutilização de resíduos têxteis, como matéria prima para produção de produtos de vestuário, decoração, brinquedos, entre outros, com o uso de técnicas artesanais da cultura local.

O projeto Capacitação em Ecomoda foi desenvolvido de acordo com as propostas do programa de Extensão Ecomoda UDESC que foi criado com o propósito de contribuir com a sociedade na pesquisa de métodos e técnicas para reduzir os impactos socioambientais ligados à indústria do vestuário. O objetivo do programa é contribuir com a sociedade através da educação, com pesquisa e atividades de capacitação, através da inter-relação entre o meio 
acadêmico e a comunidade, desenvolvendo noções de responsabilidade socioambiental na produção e consumo de produtos ligados ao universo da moda, e possibilidades de geração de renda (SCHULTE, p. 123, 2015).

\section{CONCLUSÃO}

O design tem o potencial para mudar o mundo. Tudo o que for criado por um designer deve fazer mais do que simplesmente cumprir a sua finalidade. Importa também melhorar a qualidade de nossas vidas sem prejudicar o planeta (CHICK, p. 14, 1992).

Conceber produtos considerando a redução dos impactos ambientais gerados pela indústria da moda, durante todo ciclo de vida dos produtos do vestuário, da matéria-prima até o pós-uso, é fundamental para minimizar danos socioambientais. Ao se reduzir a produção de novos materiais, em cada etapa da cadeia têxtil e de confecção, se reduz o consumo de recursos naturais que muitas vezes não são renováveis. A ampliação do tempo de vida dos produtos, ao máximo, também contribui para sustentabilidade. E quando os produtos forem descartados é preciso que sejam reutilizados, ou reciclados para se tornar matéria-prima para novos produtos.

As crises econômica e ambiental, certamente contribuíram para a mudança no comportamento de consumo. A quantia investida no consumo passa a ter importância e, por consequência, o produto será mais cuidadosamente avaliado pelo consumidor antes da compra (SCHULTE p 38, 2015).

A intervenção da customização e outras técnicas trabalhadas no projeto de Capacitação em Ecomoda agregam valor estético e emocional aos produtos, e se amplia o tempo de vida de peças do vestuário. $O$ reuso de resíduos têxteis em produtos de empreendimentos de Economia Solidária, proporciona trabalho e renda para pessoas que necessitam de oportunidades para se reintegrarem socialmente, além disso, se resgata técnicas artesanais da cultura local.

Contudo, Bonsiepe (2011) afirma que "a distância entre o que é socialmente desejável, tecnicamente factível, ambientalmente recomendável, economicamente viável e culturalmente defensível é a contradição mais forte à qual a atividade projetual está exposta" (SCHULTE, p. 94, 2015).

\section{REFERÊNCIAS}

Abit. Perfil do setor: dados gerais do setor atualizados em 2016, referentes ao ano de 2015. Disponível em:<http://www.abit.org.br/cont/perfil-do-setor $>$. Acesso em ago. de 2016.
AMARAL, M.C.; FERREIRA, A. C.; BARUQUE-RAMOS, J.. A política nacional de resíduos sólidos e a logística reversa no setor têxtil e de confecção nacional. In: 2o CONTEXMOD - Congresso Científico Têxtil e de Moda, 2014, São Paulo - SP. Anais do 2o CONTEXMOD. São Paulo SP, 2014.

BARBOSA, R. N. de C. A economia solidária como política pública: uma tendência de geração de renda e ressignificação do trabalho no Brasil. São Paulo: Cortez, 2007.

CASTRO, B. G. A economia solidaria de Paul Singer: a construção de um projeto político. Dissertação. Universidade Estadual de Campinas - Instituto de Filosofia e Ciências Humanas. Campinas, SP. 2009.

FARIA, José Henrique de. As organizações coletivistas de produção associada e a autogestão social. Disponível em <http://eppeo.org.br/wp-content/uploads/2011 /10/FARIA-As-OCPA-e-a-Autogest\%C3\%A3o.pdf $>$ Acesso em set. de 2016.

FREIRE, Estevão; LOPES, Guilherme Bretz. Implicações da Política Nacional de Resíduos Sólidos para as práticas de gestão de resíduos no setor de confecções. Redige: revista de design, inovação e gestão estratégica, v.4, n.01, abr. 2013.

IEMI.Relatório Setorial da Indústria Têxtil Brasileira. São Paulo: Instituto de Estudos e Marketing Industrial, Brasil Têxtil, 2001.

MARTINS; S. B.; PEREZ; I. U. Estratégias para a redução de resíduos no setor de confecção de produtos de moda. In: VIII COLÓQUIO DE MODA, Rio de Janeiro, 2012.

MENEGUCCI. Franciele, et al. Resíduos Têxteis: Análise sobre descarte e reaproveitamento nas indústrias de confecção. In: Congresso Nacional de Excelência em Gestão, 2015.

MTE - Ministério do Trabalho e Emprego/ SENAES - Secretaria Nacional de Economia Solidária. O que é Economia Solidária? <http://portal.mte.gov.br/eco solidaria/o-que-e-economia-solidaria.htm > Acesso em set. de 2016.

PEREIRA, José Almir Rodrigues. Geração de resíduos industriais e controle ambiental. Usp, $2014<$ Disponível em http://bit.ly/2cxQzm5 > Acesso em set. de 2016. 
PEZZOLO, Dinah Bueno. Tecidos: Histórias, Tramas, Tipos e Usos. São Paulo: Editora Senac, São Paulo, 2007.

PINHEIRO, Eliane; FRANCISCO, Antônio Carlos de. 0 desempenho ambiental e os descartes de resíduos têxteis nas indústrias de confecções - uma abordagem teórica. ABEPRO, 2013.

SCHULTE, Neide Köhler. Reflexões sobre moda ética: contribuições do biocentrismo e do veganismo. Florianópolis: Editora UDESC, 2015.

\section{UNISOL Brasil. Central de Cooperativas e} Empreendimentos Solidários. Disponível em < http:// www.unisolbrasil.org.br/>. Acesso em jul. de 2016. 